\title{
Biospecimen Findings Supplemental Qualifiers Dataset
}

National Cancer Institute

\section{Source}

National Cancer Institute. Biospecimen Findings Supplemental Qualifiers Dataset. NCI Thesaurus. Code C147189.

A dataset containing supplemental information, specifically non-standard variables, to parent records in the biospecimen findings domain. 